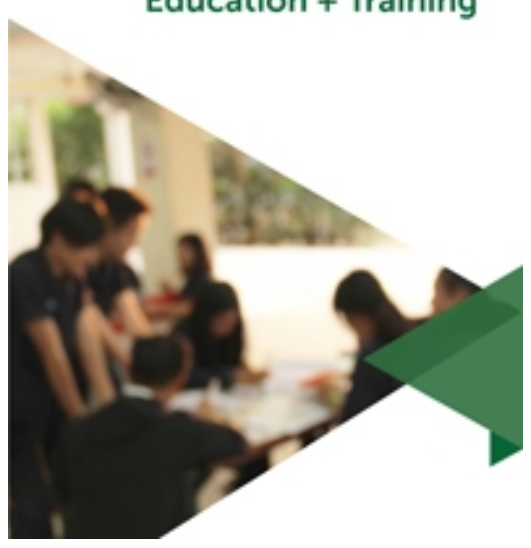

The Promise of Andragogy, Heutagogy and Academagogy to Enterprise and Entrepreneurship Education Pedagogy

\begin{tabular}{|r|l|}
\hline Journal: & Education + Training \\
\hline Manuscript ID & ET-10-2018-0211.R3 \\
\hline Manuscript Type: & Viewpoint \\
\hline Keywords: & Heutagogy, Andragogy, Pedagogy, Academagogy \\
\hline \multicolumn{2}{l}{} \\
\end{tabular}

SCHOLARONE ${ }^{\text {IM }}$

Manuscripts 


\title{
The Promise of Andragogy, Heutagogy and Academagogy to Enterprise and Entrepreneurship Education Pedagogy
}

\begin{abstract}
Purpose - This paper addresses the recent development of heutagogy in the domain of enterprise and entrepreneurship education. Responding to recent thinking within our domain of education, this paper discusses the origins of heutagogy, its adoption within enterprise and entrepreneurship education and offers suggestions as to the further development of such thinking in this domain.

Design/methodology/approach - This conceptual paper revisits the original thinking that developed the process of heutagogy, or self-determined learning. Revisiting the conceptual foundations of heutagogy, comparing it to andragogy and to the idea of academagogy enables the process of academagogical process knowledge to be outlined. Through this process, the authors argue it is possible to envisage the real potential value of heutagogy to enterprise and entrepreneurship education.
\end{abstract}

Findings - In advocating for the development of academagogical process knowledge (APK), the authors highlight the importance of six specific knowledge bases; knowledge of self, knowledge of entrepreneurship theories, knowledge of transformational learning approaches, knowledge of authentic assessment processes, knowledge of student engagement and knowledge of how to scholarly lead. The authors argue that the development of scholarship of teaching and learning for enterprise and entrepreneurship education can be advanced through these six knowledge bases.

Practical implications - There are important implications that arise for all enterprise and entrepreneurship educators in the discussions presented here. Most importantly, that heutagogy must be evaluated alongside the blended contributions of pedagogy, andragogy and academagogy.

Originality/value - This paper advances the readers' understanding of the potential role of heutagogy in enterprise and entrepreneurship education. In doing so, differing opinions related to the use of heutagogy in our domain have been addressed, and a developmental pathway outlined.

\section{Introduction}

Increasingly, the role of enterprise and entrepreneurship education (hereinafter EE) extends beyond the support of new venture creation and into the development of essential employability skills (Ustav and Venesaar, 2018) and/or graduates capable of coping with what Barnett (2018) terms, an uncertain world. With the increasing expectations that are 
placed on EE, the importance of specific scholarly practices that distinguish the domain are increasingly drawn into question; as might be expected when different institutional, educator and learner contexts are blended globally. This paper specifically looks at the interpretation and use of heutagogy in the domain of EE. Since the initial introduction of heutagogy to the domain of EE (see Jones, Matlay, Penaluna and Penaluna, 2014), the interpretation of the concept has varied to such an extent, its original meaning (see Hase and Kenyon, 2000), and therefore potential value to EE has been placed in question. The aim of this paper is to discuss the origins of heutagogy, its adoption within EE and current alternative interpretations that may restrict its future development as initially outlined by Jones et al., (2014). This paper's focus on heutagogy requires simultaneous consideration of the related terms pedagogy, andragogy and academagogy, given it is clear from the original literature (see Hase and Kenyon, 2000; McAuliffe, Hargreaves, Winter and Chadwick, 2009) that dialogic relations (Bruyat and Julien, 2001) exist between all four focus areas, and therefore it is not possible to adequately discuss heutagogy without direct reference to the other terms. As such, an initial premise in this paper is that to further the development of scholarship of teaching and learning (SoTL) in the context of EE, this broader and more inclusive consideration of contemporary educator practice is important. At this point in time, the development of SoTL in the context of EE should focus closely on our discipline context (Healy, 2000) in order to ensure the aim of explaining how learning is made possible in EE, informs the ongoing development of scholarly practice in our domain. Such an approach should accommodate geographical and context-specific differences (i.e. levels of education) that collectively comprise what EE is globally today. It should also be noted that in terms of SoTL, this paper in very sympathetic to Cranton's (2011) approach to viewing SoTL through the lens of transformative learning theory (Mezirow, 1991). 
The remainder of this introductory section will outline the basic concepts that will be subject to our consideration, with the view of subsequently contextualizing these primary concepts within the domain of $\mathrm{EE}$ as the paper proceeds, delineating each concept so that the differences between each concept are clearly understood. Through proceeding this way, misunderstandings that have begun to creep into our literature can be identified and addressed; action argued essential to furthering the development of sound SoTL in the domain of EE. Let us briefly consider the nature of pedagogy, andragogy, heutagogy and academagogy as they appear in the broader educational literature.

\section{Pedagogy}

Since at least Hall (1905, p. 375), the educational literature has distinguished between the term pedagogue (a person who leads the child to and from school) and the term pedagogy, a word derived from pedagogue. For more than a 100 years, the term pedagogy describes "the methods of teaching or imparting knowledge or instruction generally on the one hand-all those processes by which information is given-and on the other, education or development from within outward". Put simply, pedagogy relates directly to the agency that educators expend in order to develop agency in students, be that subject specific or more broadly as it pertains to the adventures of students in life. Educators who develop deep knowledge of their pedagogical methods, within the context of a specific domain of inquiry, are often observed to be developing pedagogical content knowledge (Shulman, 1986). Within specific domains of inquiry, signature pedagogies (Shulman, 2005) often develop that characterise standardised approaches to instruction of particular disciplines (e.g. in medicine, law and/or engineering). In 
essence, when the authors speak of pedagogy, we are referring to the planned actions of the educator seeking to aid the learning of those students they are responsible to.

\section{Andragogy}

Popularised by the works of Knowles (1968; 1980), andragogy commonly is associated with student behaviour that is self-directed in nature, although still anchored to the direction of the educator. Such contemporary approaches build directly from the pioneering works of Knapp (1833) that defined the term, and Lindeman (1926) and Anderson and Lindeman (1927) who first developed the fundamental principles of adult learning. It is important to appreciate the divide that still exists between generally the "teaching procedures" of Knowles (Brookfield, 1984 p. 190) and the philosophical positioning of Lindeman vis-à-vis how and when andragogy is used productively in educational settings; as will be discussed in more detail shortly. For now, the authors posit that andragogy is related to self-directed learning where the students assume greater responsibility and autonomy for learning outcomes vis-àvis traditional pedagogical approaches.

\section{Heutagogy}

Developed by (Hase and Kenyon, 2000), heutagogy refers to self-determined learning where the individual student's interests and motivations create a focus area for new learning that is (at that point in time) independent of the educator. Inspired by the student-centered ideas of Carl Rogers, constructivism, and Stephenson's (1994) notion of capability, Hase and Kenyon championed this new approach, overtime seeing the importance of human agency to the process of education (Hase and Kenyon, 2007; 2013), just as it is to humanism and 
constructivism (Blaschke, Kenyon and Hase, 2014). Here, heutagogy is differentiated from andragogy in terms of who frames that starting point for learning to occur, in andragogy there is an educator, in heutagogy there is a student.

\section{Academagogy}

With direct reference to pedagogy, andragogy and heutagogy, by way of dialogic relations, the concept of academagogy is used as a mediating process of scholarly leading to balance the use of all three gogies. In identifying the challenge of removing the educator from the equation when applying heutagogical methods, McAuliffe et al., (2009) coined the term academagogy to propose a form of scholarly leading they saw as necessary to balance the integration of pedagogy, andragogy and heutagogy as necessary within the learning of any individual. Therefore, academagogy is the blended use of pedagogy, andragogy and heutagogy, guided by educators in cooperation with students whose learning needs are assumed to differ.

While pedagogy, andragogy and heutagogy (PAH) have been viewed as forming a PAH continuum (Garnett \& O’Beirne, 2013), McAuliffe et al., (2009) viewed the process of academagogy as "operating at a meta-level, above the PAH continuum" (Jones et al., 2014, p. 771). When heutagogy was first introduced into the domain of EE (Jones et al., 2014) the process of academagogy was argued to be fundamentally important to the use of heutagogy in EE. Figure 1 provides a succinct summary of the contrasting relationships between all four concepts discussed thus far. The remainder of the paper will now discuss the origins of heutagogy, its adoption within EE and alternative interpretations that have emerged in the EE literature. The discussion that follows therefore aims to provide additional clarity around the use of pedagogy, andragogy and academagogy in the hope that the anticipated contribution of 
heutagogy in EE can be more fully appreciated.

\author{
Insert Figure 1 about here
}

\title{
The spirit of heutagogy
}

As conceived by Hase and Kenyon (2000), heutagogy is a termed coined to describe learning that is initially self-determined by learners, not initially led by educators. In many ways this may be construed to be nature's way of learning, where curious learners explore their environments and contexts. Developed initially for distance education, heutagogy has now been applied to a wide range of educational contexts, both in terms of disciplines and levels of education. The development of heutagogical guidelines has continued over the past 18 years, and is summarised below in Table 1, as per Blaschke and Hase (2015, p. 32)

\section{Insert Table 1 about here}

Through these design guidelines, students are encouraged to explore many avenues of learning. Learners are also supported to create many types of artefacts and systems that express the learning and related activity. Learners are encouraged to collaborate with others to increase the avenues for learning, and therefore, connecting with others is critically important (Bhoyrub, Hurley, Neilson, Ramsay and Smith, 2010). Thus, a process of sharing is actively encouraged to increase opportunities for collaboration. Finally, learning is seen as benefiting directly from students engaging in enhanced critical reflection, to enable new frames of personal and societal reference to be developed. 
It is the authors' experience that that heutagogy is a natural process for educators in our domain that seek transformational learning outcomes; but not often a natural learning process for students who feel pressured by internal and external forces and/or educators who feel compelled to act in ways that align to the more traditional passive approach common in higher education. Such outcomes are sadly consistent with that observed elsewhere (see Bottery, 2004) where institutional norms shape the limitations of students. Nevertheless, the direct value of heutagogy to EE seems obvious, as noted recently by Morselli (2018). In relation to learning, people themselves play an immediate and ongoing role in what, when and how they learn, and their interests should not be quarantined from the learning process. In the current age of increasing complexity, this has the added benefit of ensuring that lifelong and/or lifewide learning (Barnett, 2011) is an achievable goal. Thus, heutagogy is argued to be a fundamentally important element of transformational learning in any EE context.

\section{Alternative interpretations of heutagogy}

Since 2014, several papers have incorporated the idea of heutagogy, or self-determined learning into their consideration of phenomena in the domain of EE (Tosey, Dhaliwal and Hassinen, 2015; Hägg and Kurczewska, 2018; Kapasi and Grekova, 2018; Neck and Corbet, 2018). From the perspective of these authors, very few have done so in ways that align with the interpretation of pedagogy, andragogy, heutagogy and/or academagogy as outlined above. The positive here however is that educators in our domain are recognizing the need to pedagogically reorient their students' learning in ways that are self-determined and aligned to the natural interests of their students; a practice fundamental to the process of academagogy. The following examples illustrate the problematic nature of incorporating heutagogy into an 
EE context without the accompanying process of academagogy and/or of confusing heutagogy for andragogy.

In their recent paper on the SoTL in EE, Neck and Corbett (2018, p. 32) conclude, with direct reference to andragogy and heutagogy, "pedagogy however, represents EE of the past". By excluding the process of academagogy, they (perhaps unwittingly) have positioned pedagogy as an isolated element of a process that is clearly dynamically blended with andragogy and heutagogy. Neck and Corbett's interpretation appears to view the PAH continuum as linear, rather than iterative and flexible. This position may be representative of the instructional dominance of entrepreneurial training that is often observed in American institutions, rather than the transformative learning common to enterprise education increasingly seen elsewhere. It may also represent the differing goals of teaching to be an entrepreneur, as opposed to creating learning environments that support the development of the entrepreneurial individual. Therefore, it would seem that further clarity around the role of pedagogy in the approach outlined by Neck and Corbett is required.

Drawing on the self-determined approach of Jones et al., (2014), Kapasi and Grekova (2018) explored the views of EE students towards self-determined learning, an admirable research project. However, the conceptualization of what is self-determined learning is vague and discussed as an 'either or' alternative to traditional pedagogical instruction. Again, in the absence of incorporating academagogy as the mediating process through which pedagogy, andragogy and heutagogy are blended, it is not possible to evaluate the effectiveness of heutagogy in EE. In this instance, Van Gelderen's (2010) use of Self-Determination Theory (see Ryan and Deci, 2000) is used as a direct substitute to Hase and Kenyon's (2000) approach to self-determined learning, despite no specific connection between both 
approaches (see Hase, 2014). Further, other cited connections to self-determined learning in EE (Tosey, Dhaliwal and Hassinen, 2015 and Bird (2002)) have no established connection to either the literature or practice of self-determined learning, rather they relate respectively to team learning and andragogy.

The final example is the recent work of Hägg and Kurczewska (2018) who in considering the interplay between pedagogy and andragogy propose a continuum for both processes. Whilst acknowledging the fluid movement between both pedagogy and andragogy, heutagogy is seen as a step too far and the process of academagogy, still applicable to pedagogy and andragogy, also is not incorporated. Brookfield (1986, p. 122) identifies the challenge with such a position when he states "the act of facilitating learning, however, is one that is sufficiently complex and challenging as to make us suspicious of any prepackaged collections of practice". In all three examples, the integrity of the initial link between Jones et $a l .$, (2014) and the heutagogy literature, for example Hase and Kenyon, (2000; 2007; 2013) and Blaschke, Kenyon and Hase (2014), could have been retained through the incorporation of academagogy and/or greater familiarity with the heutagogy literature. Indeed, the initial introduction of heutagogy into EE (Jones et al., 2014) is misrepresented as requiring educators to choose between pedagogy, andragogy and/or heutagogy, when indeed the opposite is the case. To address these concerns, this paper now proposes 1) a baseline focus on the process of student agency and 2) the development of academagogical process knowledge (APK) as two positive ways to use heutagogy in EE in ways consistent with the broader heutagogy literature.

\section{Combining the gogies to develop agency}


As illustrated in figure 1, the iterative nature of all four gogies can be visualized. The pedagogy box relates to any instruction fully under the control of the educator. For example, specific areas of focus, specific learning activities, and specific methods and/or timing of assessment. In the heutagogy box there is the student's desire to activate their learning in areas specific to their interests and/or needs, and which may be stimulated by the educator's ability to raise curiosity. The andragogy box relates directly to the need for constructive alignment (Biggs, 1999) and related resource and responsibility alignment to guide a process of self-directed learning (Author, 2019) in ways that support student agency. Within the context of this paper, the assumed purpose of EE is to develop some degree entrepreneurial agency, and it is important that the nature of such agency is explain before the discussion proceeds further.

There is a potential problem in viewing entrepreneurial agency as directly connected to the individual ability to discovery and create new opportunities (Garud and Giuliani, 2013) and/or institutional contexts (Jennings, Lounsbury and Sharifian, 2015). While these approaches advance our understanding of entrepreneurial behaviour in broad and complex settings, such contexts do not always easily transferred to all levels of student learning. Instead, this paper proposes that a simpler form of entrepreneurial agency can be grounded in Bandura's (2006, p. 164) seminal notion of human agency. For Bandura, humans can use cognitive self-regulation (or agency) to "create visualized futures that act on the present; construct, evaluate and modify alternative courses of action to secure valued outcomes; and override environmental influences". The four core properties of human agency that Bandura identifies (intentionality, forethought, self-reactiveness and self-reflectiveness) align neatly to self-directed individuals acting with conviction and demonstrating perceptional awareness of their social surrounds, a common learning outcome associated with many EE programmes. 
The recent notion of self-negotiated action (Author, 2019) offers a middle position argued to be amenable to both Bandura's (2006) human agency and those more advanced notions of entrepreneurial agency noted above (Garud and Giuliani, 2013; Jennings, Lounsbury and Sharifian, 2015). Building on Jones's (2011) use of the reasonable adventurer approach (i.e. developing graduate students capable of creating opportunities for satisfaction throughout his or her life (Heath, 1964)), this paper positions the pursuit of opportunities for personal satisfaction (developmentally) in front of the pursuit of opportunities for new value creation. In this context, the authors see new value creation as occurring through either new business creation and/or, creating something of value for other stakeholders. Thus, entrepreneurial agency is aligned with self-negotiated action, defined by Author $(2019$, p. 58) "as the agency individuals demonstrate in directing their conscious thinking and action towards an alignment of their inner and outer worlds in order to succeed in life". Therefore, the development of self-negotiated action, like the development of other related competencies and/or capabilities, can be positioned as proceeding entrepreneurial action. This positioning does not ignore the importance of any form of value creation; rather, it simply recognizes the temporal importance of the developing sufficient agency in order to support any subsequent value creation.

The authors acknowledge that this position may be too narrow for other educators in our domain of education, with other colleagues already preferencing the development of value and/or new ventures creation (see Lackéus, 2018; Neck and Corbett, 2018) as the primary focus and purpose of EE. In the context of this paper, the opportunity for blended PAH learning where learners move from dependency-based learning towards autonomous learning 
as required, fits nicely with the emerging competency and capabilities approaches in EE, such as the 'EntreComp' approach of Bacigalupo, Kampylis, Punie and Van den Brande (2016).

Both the development of value and/or new ventures creation require the presence of human agency, but it is important to note that human agency is not dependent on the development of value and/or new ventures creation. By any reasoning, the development of value and/or new ventures creation is epiphenomena of human agency, that is, it is the by-products of human agency. Therefore, given the unpredictable nature and success of developing new value and/or new ventures creation, the authors contend that the purpose of EE should also be something more predictable, something logically obtainable through a process of education, and something that is measurable within the window of a student's tenure; in the context of this paper, that something is human agency. Although beyond the scope of our paper, the educational literature on teaching for the development of creative endeavor has much to offer, and mirrors much of this debate. For example, evaluation methods such as Consensual Assessment Techniques question whether we are looking at the successful outcome or product, as opposed to success of the learning (Amabile, 1982).

Therefore, the authors support the view that EE can validly be viewed in the first instance as a process of education that develops an increased capacity for self-negotiated action. From this minimal position, the fundamental nuances of both enterprise and entrepreneurship education are addressed vis-à-vis the enormous variance of practice found globally in EE. In this sense, EE is more of a method for developing agency than it is a stand-alone subject area. The challenge here rests with the ability to use transformative learning (Mezirow, 1978) processes to develop deeply reflective students that can see both themselves and their surrounds in new ways. From this perspective, EE's purpose is to create an educational 
opportunity, using authentic student-led experiences, to develop various competencies and attributes through which entrepreneurial agency (or capability) is enhanced. Such an adjustment in the habits of mind cannot be achieved solely through a pedagogic approach, no matter how gifted the educator. It cannot be achieved solely through a heutagogic approach, no matter how determined the student. It cannot be achieved solely through an andragogic approach if the student has not been sufficiently trained and supported in the use of transformative learning processes. Only when all three gogies are combined in a state of flux (i.e. educator inputs, student enthusiasm and agreed responsibilities regarding resources and desired outcomes) can a capacity for self-negotiated action, and/or other forms of agency be deliberately curated.

To be clear, the authors assert that the development of agency requires the infusion of heutagogical and pedagogical inputs, and that heutagogy and pedagogy form an essential pathway to andragogy, as mediated by the process of academagogy. In figure 1 , it is the process of academagogy that makes possible the vital relations between each gogy box. The educator's knowledge, skills and practice matter only in so far as they can match the requirements of the individual student's curiosity, passion and aspirations. Both the educator and the student are also dependent upon the educational process becoming self-directed in an andragogical sense. EE can neither be just pedagogical nor only heutagogical. Rather, in the spirit of Brookfield (1984) and therefore, Lindeman (1926), there is an essential pathway of self-directed learning (andragogy) that is mediated by the educator's knowledge, skill and practice vis-à-vis the individual student's curiosity, passion and aspirations. Just as Lindeman argued for the elevation of situations over subjects, the value and meaning associated with key aspects of the EE student's learning can be viewed as unknowable a priori to the actual experience. Adopting such a position does not lessen the pedagogical role of the educator, 
indeed, quite the opposite. The process of scholarly leading, or academagogy, requires that the educator be attuned to both the personal and cognitive development needs of each student. Therefore, the educator's role is one of moderating their leadership, mentoring and overall support to their students' adventures. Viewed in this way, the development of academagogy is clearly of great importance to all educators attempting to blend and utilize the three primary gogies in an appropriate manner.

\section{The importance of academagogy}

Our talents as educators must span from the simple to the complex and be applicable to both young and mature students. Our effectiveness in this respect will largely be based on our ability to let go of our desire to control, as and when it is appropriate. As educators, we must cede ground to our students, if only to enable them to show their true self through experimentation. Further, we must accept that we cannot know everything our students need to know. This can be a confronting experience, but if educators are to transition from controlling academic to scholarly leading, they must give up some control initially. In reality, the educator always has control, but it is a different form of control. The educator can't control their students' hearts and minds, but they can offer students the opportunity to enrol in a process that seeks to support them.

As previously noted, for the authors, pedagogy relates directly to the agency that educators expend in order to develop agency in students. Given that this simple description accommodates endless practices and philosophical positions, it would seem prudent that each educator be free to internalize the use of the term pedagogy as it relates to their own practice. It is however appropriate to consider the essential principles of heutagogy, andragogy and academagogy; noting, it is important to tread carefully here. While there is an 
increasing body of literature related to heutagogy, there are many educators that default to contemporary ideas of andragogy as an opposite of pedagogy. There is also very little literature on the process of academagogy, despite its apparent obvious importance to uniting the processes of pedagogy, andragogy and heutagogy. First, let us again consider the basic principles for heutagogy (see Hase and Kenyon, 2013) in Table 2 below.

\section{Insert Table 2 about here}

Letting the learner's needs and interests naturally start the learning process ensures relevance and appropriateness. What other methods might you use to elevate the learning process beyond knowing and doing? Reflection is a key process here, noting that, your students will spend considerably more time living outside of your classroom than in it. Be mindful and supportive of the learning experiences they have outside of the classroom. Consider how you can encourage your students to take more risks with their learning. Ensure your students have opportunities to share their learning and its relevance within the context of their developing selves. Finally, make learning fun so that it might inspire more learning. With these principles in mind, the process of andragogy can be considered from the perspective of Lindeman, as explained by Brookfield (1984), to side step seeing andragogy as a different form of teaching practice, instead viewing it more philosophically from the perspective of the student.

\section{Insert Table 3 about here}

Andragogy can be viewed as another form of reasoning used across and within the process of EE. Figure 2 highlights the critical importance of scholarly leading in 


\begin{abstract}
supporting the development of students, capable of self-negotiated action, via a process of andragogical self-directed learning.
\end{abstract}

\title{
Insert Figure 2 about here
}

Again, EE should not just be driven by pedagogical or heutagogical processes. Rather, an essential pathway of self-directed (or andragogical) learning (mediated by the educator's knowledge, skill and practice) vis-à-vis the individual student's curiosity, passion and aspirations is required. As already stated, the process of scholarly leading, or academagogy, requires that the educator is attuned to both the personal and cognitive development needs of each student. Therefore, the educator's role is one of moderating their leadership, mentoring and overall support to their students' adventuring. Whilst this may appear to be a vunerable position to the inexperienced, it enables the flexibility and adaptabilty that emulates decision making in real world environments where not everything can be kept under control, nor remain stagnent in the face of change. This has the added advantage of letting the student demonstrate that they can be reflexive active learners who can pivot when a situation demands it.
A significant part of such scholarly leading is ensuring the students' perspectives of life are sufficiently challenged to ensure untested assumptions are not carried forward into their adventuring. Ragin (1994) outlines how our individual 
representations of life form naturally from the (mostly inductive) personal experiences we have and through the (mostly deductive) ideas and theories we gravitate towards. However, as Peirce (1908, p. 104) noted, our initial assumptions often arise through "spontaneous conjecture of instinctive reason". Peirce used the phrase retroduction to describe a form of reasoning whereby an initial thought process through which the provisional plausibility of something is held to be possible. For Peirce, such journeys via retroduction are essential for the development of new ideas from which deductions can be drawn and compared against future observations. At no point is the student afforded security from the retroduction process, merely the confidence to "enter ... [a] ... skiff of musement ... [and to] ... push off into the lake of thought" (1908, p. 95). It is in these shallow waters that the skill of the educator comes to the fore, guiding the student to focus their assumptions on the realities of life, to pivot or drop their idea as the realities of their circumstances determine. In this context, the role of the educator is shepherding their students towards a mode of self-directed learning through which the underling realities of their thinking can be revealed. Or as Lindeman argued, "life becomes a creative venture in proportion to the amount of intelligence which accompanies conduct" (1926, p. 25). You can't buy or borrow a disposition towards self-negotiated action, and therefore educators need to ensure their students develop the learning habits related to such a disposition. 
Therefore, for each educator, there is a need to find a philosophical connection to andragogy. It is acknowledged that others might prefer the more educator-focused approach (see Neck and Corbett, 2018), as championed by Knowles (1968). The fact that you can contemplate your students' development in terms of becoming self-directed is a good start. The fact that you appreciate you cannot force this development is even more important. In terms of speculating as to the principles of academagogy, any such principles (as outlined in Table 4 below) should be informed by, and philosophically consistent with the importance of students developing their own social, human and financial capital, rather than relying on the dearth of directly related published work.

\section{Insert Table 4 about here}

\section{Developing academagogy}

The authors' assert that EE as a domain must move beyond the individual differences found within its increasingly porous boundaries. The argument is not that value creation and new venture creation are not valid outcomes of EE; rather, that drawing attention to the human capability that underpin such outcomes and/or capabilities can only be achieved through a good understanding of educational practice. Therefore, it would seem logical to preference the development of the prerequisite capabilities associated with different forms of new value/new venture activities prior to student engagement with value creation pedagogies. Here the domain of EE could benefit from reexamining our various starting points and definitions in conjunction with educationalists not attuned to educating for success in business, but rather personal development. 
For example, imagine if EE programmes were evaluated at the cohort level in terms of overall learning outcomes, rather than on the basis of the achievements of a few student outliers. It is increasingly common for EE programmes to be ranked on; the number of; 1) the number of faculty with entrepreneurship experience, 2) the number of student startups, and 3) how much capital has been raised by student startups (Entrepreneur.com, 2019). Alternatively, it is very rare to hear of programmes evaluated on the basis of the collective knowledge, skills, capability and/or wisdom developed within and across entire cohorts. The authors' concur with Neck and Corbett (2018) that the domain of EE needs to develop a deeper level of SoTL. This should potentially advance many educational aspects that may so far have been overlooked. Doing so would logically place the learning, not teaching, at the forefront of our scholarship. The development of an educator's SoTL is an on-going and complex process. Few individuals develop their SoTL gradually. Often, educators are struck by epiphanies that reorient their knowledge bases, which in turn alter their practice and subsequent outcomes. However, there is unlikely to be any magical advice or silver bullet to help educators to neatly define their purpose and/or EE related scholarly practice. Nevertheless, there are many wonderful examples of scholarly thinking (Shulman, 1986; Healey, 2000; Trigwell and Shale, 2004) that can guide our collective thinking about such complex issues.

\section{From knowledge to process}

Although pedagogical content knowledge (Magnusson, Krajcik and Borko, 1999) has previously being considered in our domain (Jones et al., 2014), the use of academagogy in EE would seem to require a more expansive approach. Recently, the notion of academagogical process knowledge (APK) has been advanced (Author, 2019) to address the expanded use of transformational learning in EE, extending the educator's focus beyond 
content to also include the process of deep learning. From a Mezirowian perspective (see Cagney, 2014), transformative learning outcomes require students to 1) experience a disorienting dilemma, 2) alienation from prescribed social roles, 3) re-framing of their conception of reality, and 4) re-integration into society with new perspectives. Exactly the type of ontological turn that Barnett (2004) argues is required to adapt and succeed in the unknowable worlds our students increasingly experience. Just as constructive alignment can be viewed from the perspective of both the educator and the student (Biggs, 2017), so too can knowledge be viewed in terms of content and/or process. Moving away from a strict content focus enables educators in our domain to develop their SoTL by conjointly developing knowledge of pedagogy, heutagogy, andragogy and, in turn, transformational learning, as illustrated in figure 3.

\section{Insert Figure 3 about here}

It is important to appreciate that APK includes the educator's selfhood (Palmer, 1998), and it also includes their general philosophy to life as applied to their vocational calling. Thus, there is no off-the-shelf APK that can be acquired through an apprenticeship of observation (Shulman, 2005). Author (2019) argues that simultaneous development of SoTL and APK starts with the authority each educator claims in terms of their identity and integrity. Just as Dewey (1916) saw education as a continual process of reorganising and reconstructing experience, a similar process can apply to the educator who is developing their own APK. In figure 3, there are six specific portfolios that require development. First, there is a portfolio related to the educator's self, their identity and their recognition of the philosophies that comfort and guide their life. In this area, the development of the educator's selfhood and their ability to enact philosophies is argued to be commensurate to the degree of interest they 
commit to their own conduct; there can be few shortcuts in this respect. This portfolio represents the heartbeat of an educator's APK; it governs the preferences, choices and ultimately, the nature of their students' learning experience.

Second, there is a portfolio related to developing one's knowledge of transformational learning theories/approaches. To the extent that knowledge in this area is too shallow, it's far less unlikely that an educator could develop sufficient knowledge of the other five portfolios. The educator's ability to help their students discover and explore their inner worlds and successfully achieve alignment with their outer worlds should be central to their claims of being effective in the domain of EE. Once educators step beyond teaching about, into the realms of teaching for and through, they are duty bound to close the loop, to ensure the student experience has been both reorganized and reconstructed. There now exists a rich body of literature on transformative learning and perspective transformation (Mezirow (1978; 1991; Cranton, 1994; 2016; Kegan, 1994; Brookfield, 1995; Taylor, 1997). The challenge within this portfolio is to understand how these ideas and approaches can be used to guide the development of one's scholarly practice.

Third, The educator's knowledge of EE related theories and concepts are next. There are economic theories related to market organization and disruption (Astley and Van de Ven, 1983), psychology-based theories related to mental and emotional aspects of entrepreneurial behaviour (Shepherd, 2003), and theories of strategy based on resource acquisition and use (Teece, 2018), all of which converge upon many theories of opportunity recognition/exploitation (Davidsson, 2015). There are many types of entrepreneurial behaviour that are linked to social, ethical and career considerations, context and technological change (Bird and Schjoedt, 2009). There are planning and assessment 
approaches (Cox, 2014) and the various other components that feed into such work. There are also theories and processes for financing and legal protection (Fraser, Bhaumik and Wright, 2015). A working knowledge of these theories and concepts is essential, as is an appreciation of how and when they relate to each student's learning journeys.

Fourth, the educator's knowledge of the different types of assessment in EE is critically important. This is a complex area, where pure knowledge is often diluted by the requirements of institutional norms and other external considerations, such as accreditation. There is also the hierarchical nature of outcomes related to EE where it is very common in EE for assessment to be both performance and experience oriented, requiring students to see and do things differently as well as to explain the nature of their experience during and after the assessment task. Here, it makes sense to avoid the use of inauthentic assessment, or methods that produce little or no opportunity for students to alter their behaviour within another assessment task during the same period of learning. This is a logical desire, but one that in practice is often difficult to achieve. Therefore, the authors acknowledge that there are often challenges in being able to frame the learning experience so as to cumulatively develop awareness, skills and responses within the cohort due to institutional challenges. Nevertheless, such restrictions should not limit an educator's knowledge of how and why assessment in EE should work to continuously develop our students.

Fifth, the educator must have a sound knowledge of how students typically engage with the various forms of EE they might encounter. At the heart of EE designed to increase student agency via transformational learning, is action. However, the action often desired for students to engage in, is often foreign to their normal approach to learning about things, rather than for and through. Therefore, it is important that educators develop knowledge of how best to 
support their students to engage and make sense of the learning process, ensuring they embrace the opportunity to learn about their learning. Cranton (1994; 2016) has written extensively on the process of supporting transformational learning, and her work is directly applicable to these types of debate.

Sixth, the final portfolio relates to the knowledge educators develop regarding their personal ability to lead their students in a scholarly way, using academagogy. In this portfolio area there are fewer obvious resources to connect to. The authors draw inspiration from Palmer's (1998) notion of the courage to teach. Educators will all frequently face the challenge of a divided class, divided through a preferencing of theory over experience, being motivated or unmotivated, working together or working alone, and/or being rule breakers or rule followers. In such circumstances, it is easy to become disoriented, unsure of what would constitute the best approach. What is important is to remain focused on the needs of the individual student. Academagogy relates to EE more at the individual level than at the cohort level. The educator's ability to design choice into their curriculum will go a long way to determining the manner in which the process of academagogy is employed. The educator's starting point of knowledge development is their selfhood; it is about learning about the choices each believe matter for their students and developing strategies to lead, support and negotiate with their students.

In summary, for EE, the development of SoTL will likely be via the route of paradox, tradeoffs, internal curiosity and knowing oneself. In a world where educators seemingly have less time to organize and think about our scholarship, there are many challenges that surround the process of educators developing their selfhood. Being authentic about who they are, what their purpose is and how they plan to help others to help themselves is of fundamental 
importance; given as Palmer (1998) notes, we teach who we are. These are the hallmarks of the academagogical capable educator.

\section{Conclusion}

The aim of our paper was to trace the origins of heutagogy, its adoption within EE and recent developments that may cloud its further development in our domain. Heutagogy is an approach to student learning that exists independently of EE, and its development in EE should respects its origin and development outside our domain. What is clear is that heutagogy is not a replacement for pedagogy, but rather a process of learning that necessitates a change in the pedagogical behaviour of educators. The arguments made here are that the process of academagogy is central to any such change, and more broadly, to the development of SoTL in EE. Once the continuous relationship between pedagogy, andragogy, heutagogy and academagogy is more fully understood and appreciated in the domain of EE, deeper engagement and development of the domain's embryonic SoTL with surely follow.

Several implications arise from the above discussion. First, pedagogy is directly relevant to heutagogy, just as heutagogy is directly relevant to pedagogy. Second, there is a need for educators to determine (based on the learning needs of their students) the appropriate role for self-directed andragogical learning in their teaching contexts. Doing so will enable a clearer appreciation of the role of pedagogical and heutagogical practice in supporting EE outcomes. Third, in the absence of developing a sound capability for academagogical practice, educators need to offer alternative process-driven methods through which combinations of pedagogical, andragogical and heutagogical practice can be effectively blended. Finally, as a domain, we 
need to recognise that different teaching contexts (e.g. entrepreneurship training versus enterprise learning) will shape how the four gogies are viewed and potentially combined.

Having outlined the authors' position above, it is appropriate to pause and allow the domain to respond. No degree of superiority in this debate has been assumed by the authors, only a commitment to ensuring the potential value of heutagogy and related gogies are realized in EE. It is accepted that some sections of the EE community may preference pedagogical methods over heutagogical approaches for a variety of reasons. Nevertheless, as a domain of developing education we should be mindful to respect the developed heutagogy literature that spans nearly two decades when importing heutagogical approaches into our own teaching contexts. While much debate over the nature, role and importance of academagogy in EE is anticipated, respect for the foundational writings pertaining to what is heutagogy, and those established principles that guide its use should be at the forefront of its development in EE. Doing so should enable us to move forward together, rather than round in circles together.

\section{References}

Amabile, T. (1982), "The social psychology of creativity: A consensual assessment technique", Journal of Personality and Social Psychology, Vol. 43 No. 5, pp. 997-1013.

Anderson, M. and E. Lindeman (1927), Education Through Experience, New York: The Workers Education Bureau Press.

Astley, G. and Van de Ven, A. (1983), "Central perspectives and debates in organization theory", Administrative Science Quarterly, Vol. 28 No. 2, pp. 245-273. 
Bacigalupo, M., Kampylis, P., Punie, Y. and Van den Brande, G. (2016), EntreComp: The Entrepreneurship Competence Framework, Luxembourg: Publication Office of the European Union.

Bandura, A. (2006), "Towards a psychology of human agency", Perspectives on Psychological Science, Vol. 1 No. 2, pp. 164-180.

Barnett, R. (2004), "Learning for an unknown future", Higher Education Research \& Development, Vol. 23 No. 3, pp. 247-260.

Barnett, R. (2011), "Lifewide education: A new and transformative concept for higher education", in N. Jackson (Ed.), Learning for a Complex World: A Lifewide Concept of Learning, Education and Personal Development, Bloomington: Author House.

Barnett, R. (2018), The Ecological University: A Feasible Utopia, London: Routledge.

Bhoyrub, J., Hurley, J., Neilson, G., Ramsay, M. and Smith, M. (2010), “Heutagogy: An alternative practice based learning approach", Nurse Education in Practice, Vol. 10, pp. 322326.

Biggs, J. (1999), Teaching for Quality Learning at University, Philadelphia: Open University Press.

Biggs, J. (2017), Personal Communications. 
Bird, B. (2002), "Learning entrepreneurship competencies: The self-directed learning approach”, International Journal of Entrepreneurship Education, Vol. 1 No. 2, pp. 203-227.

Bird, B. and Schjoedt, L. (2009), "Entrepreneurial Behavior: Its Nature, Scope, Recent Research, and Agenda for Future Research", in A. Carsrud and M. Brännback (Eds.), Understanding the Entrepreneurial Mind, New York: Springer.

Blaschke, L., Kenyon, C. and Hase, S. (2014), Experiences in Self-Determined Learning, Lexington, USA: Createspace Independent Publishers.

Blaschke, L. and Hase, S. (2015), "Heutagogy, technology, and lifelong learning for professional and part-time learners", in D. Herbert and K. Dennis (Eds.), Transformative Perspectives and Processes in Higher Education, New York: Springer

Bottery, M. (2004), The Challenges of Educational Leadership, London: Paul Chapman Publishing.

Brookfield, S. (1984), "The contribution of Eduard Lindeman to the develoment of theory and philosophy in adult education", Adult Education Quarterly, Vol. 34 No. 4, pp. 185-196.

Brookfield, S. (1986), Understanding and Facilitating Adult Learning, London: Jossey-Bass Publishers. 
Brookfield, S. (1995), Becoming a Critically Reflective Teacher, San Francisco: Jossey-Bass Publishers.

Bruyat, C. and Julien, P. “(2001), Defining the field of research in entrepreneurship”, Journal of Business Venturing, Vol. 16 No. 2, pp. 165-180.

Cagney, A. (2014), “Transformative learning”, in D. Coghlan and M. Brydon-Miller (Eds.), The Sage Encyclopedia of Action Research, London: Sage Publications.

Cox, K. (2014), “Fundamental entrepreneurial planning processes: Resource assessment and opportunity evaluation", The International Journal of Entrepreneurship and Innovation, Vol. 15 No. 2, pp. 79-88.

Cranton, P. (1994), Understanding and Promoting Transformative Learning: A Guide for Educators of Adults, San Francisco: Jossey-Bass Publishers.

Cranton, P. (2011), "A transformative perspective on the scholarship of teaching and learning", Higher Education Research \& Development, Vol. 30 No. 1, pp. 75-86.

Cranton, P. (2016), Understanding and Promoting Transformative Learning: A Guide to Theory and Practice, Virginia: Stylus Publishing.

Davidsson, P. (2015), "Entrepreneurial opportunities and the entrepreneurial nexus: A reconceptualization", Journal of Business Venturing, Vol. 30 No. 5, pp. 674-695. 
Dewey, J. (1916), Democracy and Education, New York: Free Press.

Dick, B. (2013), “Crafting learner-centered processes using action research and action learning", in S. Hase and C. Kenyon (Eds.), Self-Determined Learning, London: Bloomsbury.

Entrepreneur.com. (2019), “Top 25 Best Undergrad Programs for Entrepreneurs in 2019”, available at: https://www.entrepreneur.com/slideshow/322898\#1. Accessed on 29/8/2019.

Fraser, S., Bhaumik, S. and Wright, M. (2015), "What do we know about entrepreneurial finance and its relationship with growth?”, International Small Business Journal, Vol. 33 No. 1, pp. $70-88$.

Garnett, F. and O’Beirne, R. (2013), "Putting heutagogy into learning”, in S. Hase and C. Kenyon (Eds.), Self-Determined Learning, London: Bloomsbury.

Garud, R. and Giuliani, A. (2013), “A narrative perspective on entrepreneurial opportunities”, Academy of Management Review, Vol. 38 No. 1, pp. 157-160.

Hägg, G. and Kaurczewska, A. (2018), "Who is the student entrepreneur? Understanding the emergent adult through pedagogy and andragogy interplay", Journal of Small Business Management, In Press, https://doi.org/10.1111/jsbm.12496.

Hall, S.G. (1905), "What is Pedagogy?”, The Pedagogical Seminary, Vol. 12 No. 4, pp. 375383 , 
Hase, S. (2014), “An introduction to self-determined learning (heutagogy)”, in L. Blaschke, C. Kenyon and S. Hase (Eds.), Experiences in Self-Determined Learning, Lexington, Ky: Publisher unknown, available at: https://uol.de/fileadmin/user_upload/coer/Experiences-inself-determined-learning.pdf. Accessed on 16/1/2018.

Hase, S. and Kenyon, C. (2007), "Heutagogy: a child of complexity theory", Complicity: an International Journal of Complexity and Education, Vol. 4 No. 1, pp. 111-118.

Hase, S. and Kenyon, C. (2000), From Andragogy to Heutagogy, Melbourne: Ultibase.

Hase, S. and Kenyon, C. (2013), Self-Determined Learning, New York: Bloomsbury.

Healey, M. (2000), "Developing the scholarship of teaching in higher education: A discipline-based approach", Higher Education Research \& Development, Vol. 19 No. 2, pp. $169-189$.

Heath, R. (1964), The Reasonable Adventurer, Pittsburgh: University of Pittsburgh Press.

Jennings, D., Lounsbury, M. and Sharifian, M. (2015), "Entrepreneurial agency in institutions", in T. Baker and F. Welter (Eds.), The Routledge Companion to Entrepreneurship, London: Routledge.

Jones, C. (2011), Teaching Entrepreneurship to Undergraduates, Cheltenham, UK: Edward Elgar Publishing. 
Jones, C., Matlay, H., Penaluna, K. and Penaluna, A. (2014), "Claiming the future of enterprise education", Education + Training, Vol. 56 No. 8/9, pp. 764-775.

Kapasi, I. and Grekova, G. (2018) "What do students think of self-determined learning in entrepreneurship education?”, Education + Training, Vol. 60 No. 7/8, pp. 841-856.

Kegan, R. (1994), In Over Our Heads, London: Harvard University Press.

Kenyon, C. and Hase, S. (2013), "Heutagogy fundamentals", in S. Hase and C. Kenyon (Eds.), Self-Determined Learning, New York: Bloomsbury.

Knapp, A. (1833), Platon's Erziehungslehre, als Pädagogik für die Einzelnen und als Staatspädagogik, Leipzig: Minden.

Knowles, M. (1968), “Androgogy, not pedagogy”, Adult Leadership, Vol. 16 No. 10, pp. 350-352.

Knowles, M. (1980), The Modern Practice of Adult Education, Chicago: Follett Publishing.

Lackéus, M. (2018). “What is value?'-a framework for analyzing and facilitating entrepreneurial value creation", Uniped, Vol. 41 No. 1, available at: https://www.idunn.no/uniped/2018/01/what_is_value_a framework_for_analyzing_and_facil itati. Accessed on 10/07/2018.

Lindemann, E. (1926), The Meaning of Adult Education, New York: New Republic. 


\begin{abstract}
Magnusson, S., Krajcik, J. and Borko, H. (1999), "Nature, sources, and development of pedagogical content knowledge for science teaching”, in J. Gess-Newsome and N. Lederman (Eds.), Examining Pedagogical Content Knowledge, London: Kluwer Academic Publishers.
\end{abstract}

McAuliffe, M., Hargreaves, D., Winter, A. and Chadwick, G. (2009), "Does pedagogy still rule?", Australasian Journal of Engineering Education, Vol. 15 No. 1, pp. 13-18.

Mezirow, J. (1978), "Perspective transformation”, Adult Education, Vol. 28 No. 2, pp. 100110.

Mezirow, J. (1981), “A critical theory of adult learning and education”, Adult Education, Vol. 32 No. 1, pp. 3-24.

Mezirow, J. (1991), Transformative Dimensions in Adult Learning, San Francisco: JosseyBass.

Morselli, D. (2018), “Teaching a sense of initiative and entrepreneurship with constructive alignment in tertiary non-business contexts", Education + Training, Vol. 60 No. 2, pp. 122138.

Neck, H. and Corbett, A. (2018), “The scholarship of teaching and learning entrepreneurship", Entrepreneurship Education and Pedagogy, Vol. 1 No. 1, pp. 8-41. 
Palmer, P. (1998), The Courage to Teach: Exploring the Inner Landscape of a Teacher's Life, San Francisco: Jossey-Bass.

Peirce, C. (1908), “A neglected argument for the reality of god”, The Hibbert Journal, Vol. 7 No. 1, pp. 90-112.

Ragin, C. (1994), Constructing Social Research, London: Pine Forge Press.

Ryan, R. and Deci, E. (2000), "Intrinsic and extrinsic motivations: Classic definitions and new directions, Contemporary Educational Psychology, Vol. 25 No. 1, pp. 54-67.

Shepherd, D. (2003) "Learning from business failure: Propositions of grief recovery for the self-employed", Academy of Management Review, Vol. 28 No. 2, pp. 318-328.

Shulman, L. (1986), "Those who understand: Knowledge growth in teaching”, Educational Researcher, Vol. 15 No. 2, pp. 4-14.

Shulman, L. (2005), "Signature pedagogies in the professions", Daedalus, Vol. 134 No. 3, pp. 52-59.

Stephenson, J. (1994), “Capability and Competence: Are they the same and does it matter?", Capability, Vol. 1 No. 1, pp. 3-4. 
Taylor, E. (1997), "Building upon the theoretical debate: A critical review of the empirical studies of Mezirow's transformative learning theory", Adult Education Quarterly, Vol. 48 No. 1, pp. 34-59.

Teece, D. (2018), “Business models and dynamic capabilities”, Long Range Planning, Vol. 51 No. 1 , pp. 40-49.

Tosey, P., Dhaliwal, S. and Hassinen, J. (2015), The Finnish team academy model: Implications for management education”, Management Learning, Vol. 46 No. 2, pp. 175-194.

Trigwell, K. and Shale, S. (2004), "Student learning and the scholarship of university teaching”, Studies in Higher Education, Vol. 29 No. 4, pp. 523-526.

Ustav, S. and Venesaar, U. (2018), "Bridging metacompetencies and entrepreneurship education", Education + Training, Vol. 60 No. 7/8, pp. 674-695.

Van Gelderen, M. (2010), “Autonomy as the guiding aim of entrepreneurship", Education + Training, Vol. 52 No. 8/9, pp. 710-721. 


\section{Figure 1: The Gogies}

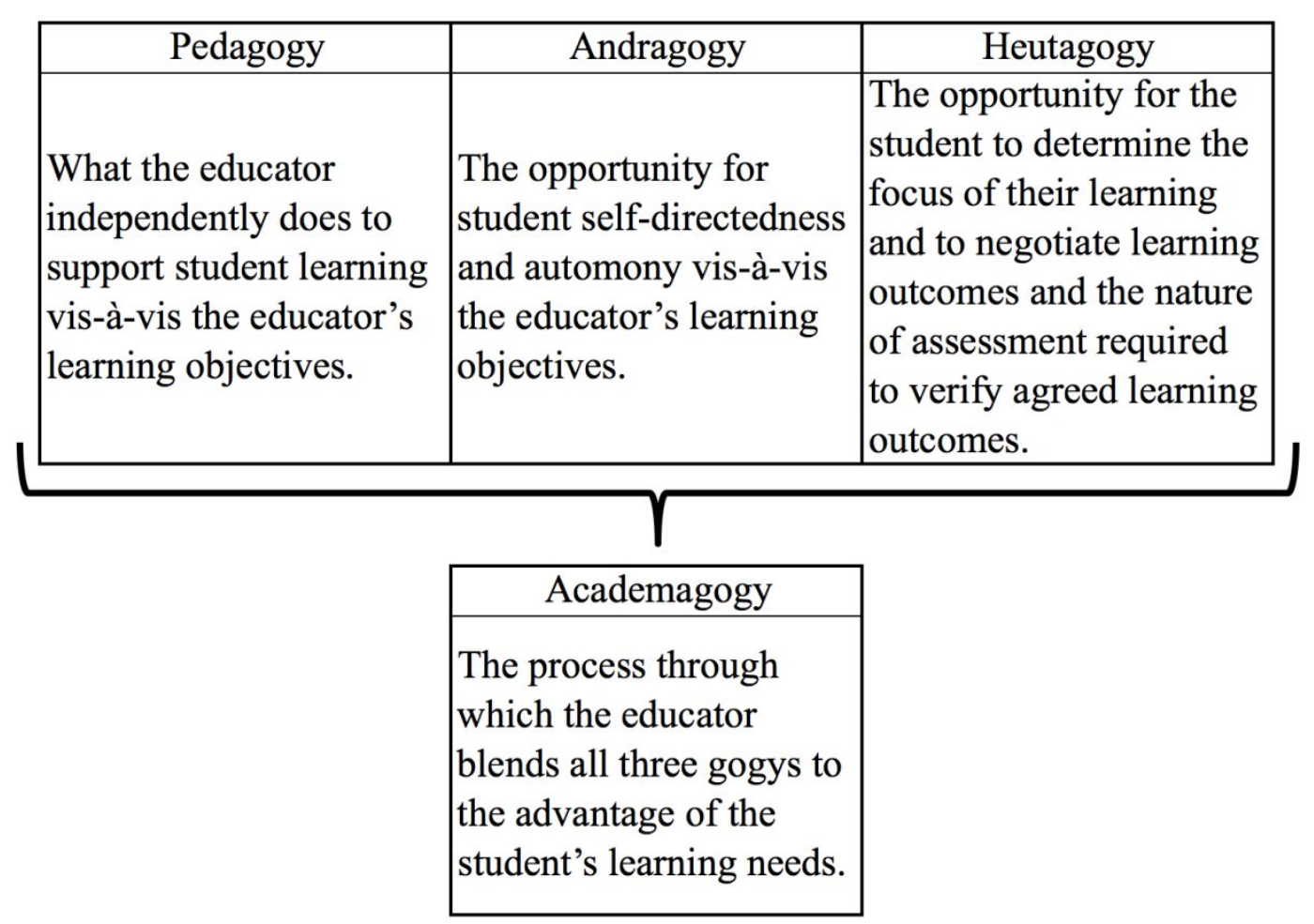




\section{Table 1: Heutagogical Guidelines}

Learners need to be involved in negotiating what and how they learn throughout the design and learning process (Kenyon and Hase, 2013).

Curricula should be flexible and take into account learners' questions and motivations and how thinking shifts as a result of things they have learned.

The learner and teacher need to work together to negotiate how learning out-comes will be assessed. Evaluation could also include forms of participative (self- and peer-) evaluation, allowing learners to learn from each other and through self-reflection (Dick 2013).

The role of the teacher is to guide the learner, providing formative feedback that is personalized according to the learner needs.

The learning environment needs to incorporate opportunities for learners to explore and reflect on what they have learned and how. 


\section{Table 2: Heutagogical Principles}

Learning when the learner is ready.

Learning requires more than knowledge and skills, it requires new connections.

Learning doesn't depend upon the teacher; it can be triggered by experience.

Learning is focused upon the student, not the curriculum.

Self-sufficiency in learning, personal exploration and risk taking.

The ability to change one's way of thinking and acting from learning.

Application of learning, making connections beyond theory.

Positive learning values, so that learning is fun. 


\section{Table 3: Andragogy Principles}

The student's participation is non-coercive and directed by the interests of the student.

The process of learning should enlighten the students to their historicity of the self vis-à-vis their environs.

Help your students to make those existential choices inevitable to acting on their immediate needs/desires.

Enable your students to experience education as a social enterprise.

Enable your students to learn with others and not in isolation.

Support your students to debate the ethical and moral issues related to their development as adventures. 
Figure 2: The Academagogy Triangle

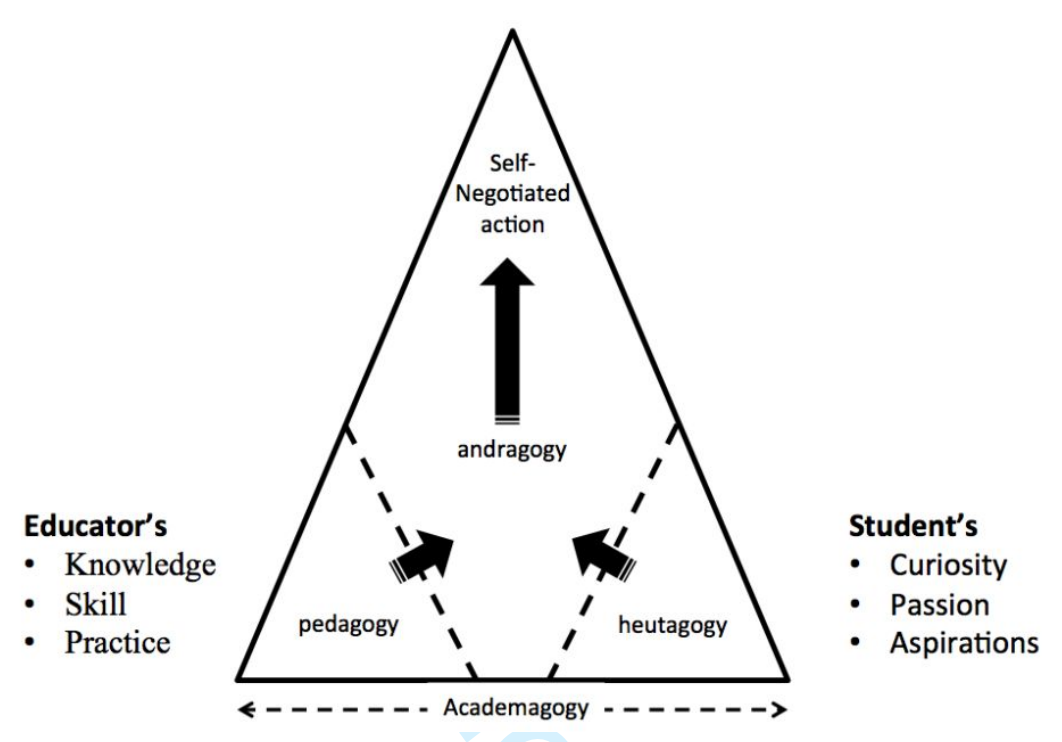

3


Table 4: Academagogy Principles

Asking your students how they would like to learn.

Appreciate the diversity in your cohort; don't expect everyone to become self-directed at the same pace.

Develop prompts to ensure you are aware of your movement between leading and supporting.

Work with your students to identify different resource requirements to support their learning.

Work with your students to identify areas of individual responsibility required to support their learning.

Ensure your students fully understand the nature of your role and what is expected from them

to become self-directed learners. 
Figure 3: Academagogy Process Knowledge (APK)

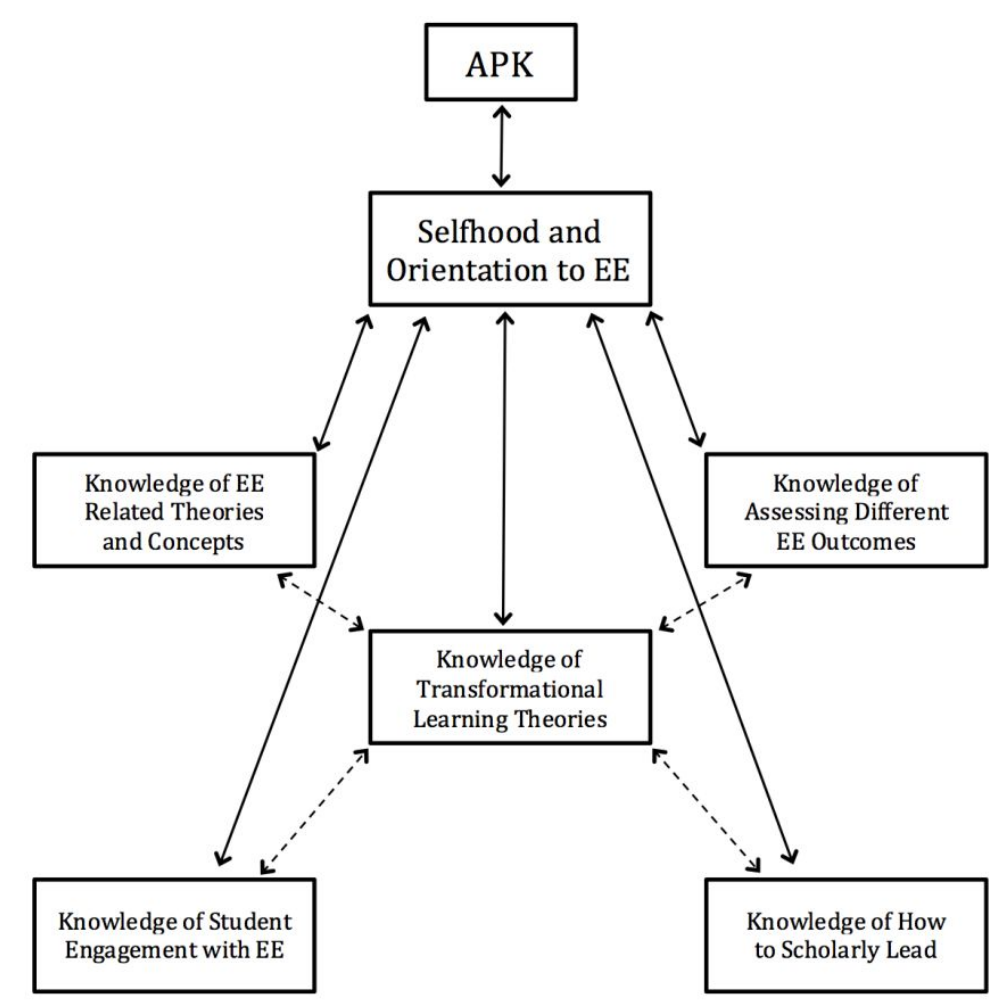

